\title{
Recrystallization Behavior of Cold Rolled Alloy 718
}

\author{
R.P. Singh, J.M. Hyzak, T.E. Howson and R.R. Biederman * \\ Wyman-Gordon Company, North Grafton, MA 01536 \\ * Worcester Polytechnic Institute, Worcester, MA 01609
}

\begin{abstract}
Recrystallization of cold rolled Alloy 718 has been studied in the temperature range of $1575^{\circ} \mathrm{F}$ $-1725^{\circ} \mathrm{F}$ as a function of strain and annealing time. Changes in the microstructure have been monitored by measuring microhardness. An increase in hardness with annealing time has been observed for the $30 \%$ cold rolled material heated to $1575^{\circ} \mathrm{F}$ and $1625^{\circ} \mathrm{F}$, whereas a continuous decrease in hardness has been observed for the $50 \%$ cold rolled material exposed to the same temperatures. Above $1625^{\circ} \mathrm{F}$, a decrease in hardness for both $30 \%$ cold rolled and $50 \%$ cold rolled material has been observed. The increase in hardness in the $30 \%$ cold rolled material heated below $1625^{\circ} \mathrm{F}$ is due to precipitation of $\gamma^{\prime \prime} / \gamma^{\prime}$ and inhibition of recrystallization. The decrease in hardness in the $50 \%$ cold rolled material appears to be due to recovery and the onset of recrystallization. Changes in microstructure in various conditions have been studied by optical microscopy and SEM.
\end{abstract}




\section{Introduction}

Recovery and recrystallization are primary processes which govern microstructural evolution in cold worked metallic systcms during high temperature anneal. These processes are well studied and documented for pure metals and model alloy systems (1-3). In commercial multiphase alloys, precipitation of the strengthening phases takes place during high temperature anneal. If the recrystallization is not complete before the precipitates have nucleated, precipitation and recrystallization exert a mutual influence upon each other $(4,5)$. Precipitate particles can hinder the formation and migration of recrystallization fronts, and the lattice defects themselves promote the nucleation of precipitates. In Alloy 718, the fcc matrix is strengthened by combined precipitation of $\gamma^{\prime \prime}$ ( an ordered $\mathrm{DO}_{22}$ structure) and $\gamma^{\prime}$ (an ordered $\mathrm{L}_{2}$ structure). In addition to these phases, delta phase ( $\mathrm{Ni}_{3} \mathrm{Nb}$ ) also precipitates and is primarily used to control creep and stress-rupture properties in Alloy 718. The delta phase is also used in ingot to billet conversion to produce controlled grain structure in the billets. The precipitation kinetics of these phases in Alloy 718 have been studiest extensively (6). However, an understanding of the role of these precipitates in recovery and recrystallization processes in this commercial alloy is lacking. In this study, recrystallization behavior of Alloy 718 in the fully solutioned and cold rolled condition has been studied and results are reported.

\section{Experimental:}

Samples from commercial Alloy 718 were machined flat to a thickness of $4.75 \mathrm{~mm}$. These strips were fully solutioned at $1900^{\circ} \mathrm{F}$ for 1 hour followed by a water quench. The solution temperature used in this study was above the delta solvus of $1850^{\circ} \mathrm{F}$. The solution anneal resulted in a single phase material with an average grain size of $40-50 \mu \mathrm{m}$. These $4.75 \mathrm{~mm}$ thick strips were further cold rolled to $30 \%$ or $50 \%$ reduction in thickness in multiple passes. Small samples were sectioned from the rolled strips and heated in the temperature range of $1575-1725^{\circ} \mathrm{F}$ for various time intervals. At the lowest temperature $1575^{\circ} \mathrm{F}$, all the three phases, namely; $\gamma^{\prime}, \gamma^{\prime \prime}$ and delta can precipitate. Temperatures in the band of $1675^{\circ} \mathrm{F}$ $1725^{\circ} \mathrm{F}$ are above the precipitation range of $\gamma^{\prime}$ and $\gamma^{\prime \prime}$, but below the delta solvus. Samples were water quenched from the exposure temperatures. Microhardness measurements using a 300 gram load were made on the samples in as-rolled and rolled + annealed condition. Samples for optical microscopy and SEM were prepared by using standard metallographic techniques (7). 


\section{Results and Discussion:}

Figures 1 (a) and (b) show representative microstructure of the $30 \%$ and the $50 \%$ cold rolled samples, respectively. For $30 \%$ rolling, grains have retained their original equiaxed shape, however, some planar markings are seen in the grain interiors. These planar markings could be slip band and / or deformation bands. With increased deformation to $50 \%$, grains have elongated and the density of the planer markings in the grain interior have increased.

The effect of annealing temperature on these structures was studied using microhardness measurements to show aging, recovery and recrystallization behavior. The variation of microhardness with time at an exposure temperature of $1575^{\circ} \mathrm{F}$ is shown in Figure 2 for both the $30 \%$ and the $50 \%$ cold rolled samples. A rapid increase in hardness for the $30 \%$ cold rolled material heated up to 1 hour is observed. After one hour hardness decreased slowly, and after 4 hours it is almost the same as the starting hardness of the $30 \%$ rolled material. After 30 minutes exposure at $1575^{\circ} \mathrm{F}$, the $30 \%$ rolled material has attained a higher hardness than the $50 \%$ rolled alloy in the as-rolled condition. In contrast to the $30 \%$ rolled material, the $50 \%$ cold rolled samples showed a rapid loss in hardness after a 15 minutes thermal exposure at $1575^{\circ} \mathrm{F}$. Hardness decreased up to 2 hours and then increased slightly.

a)

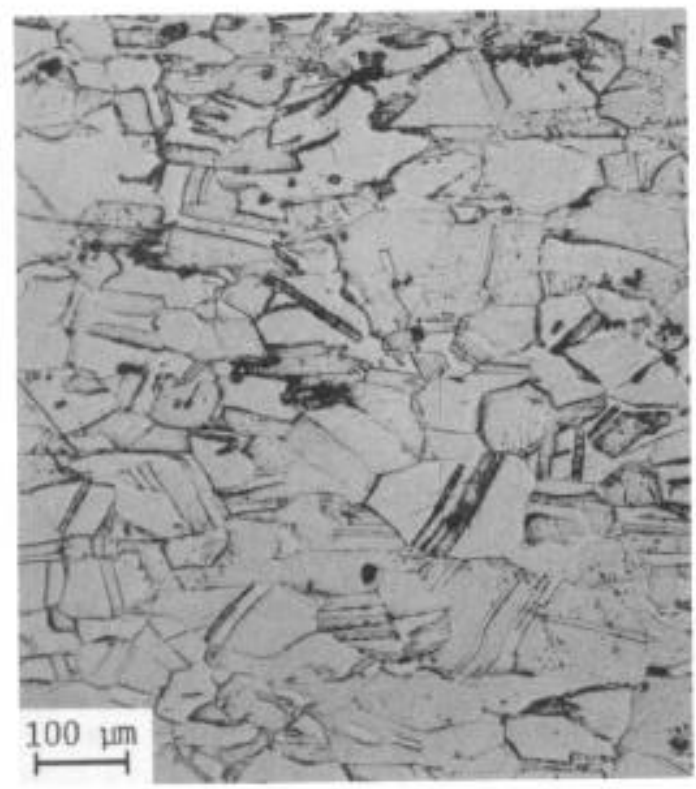

b)

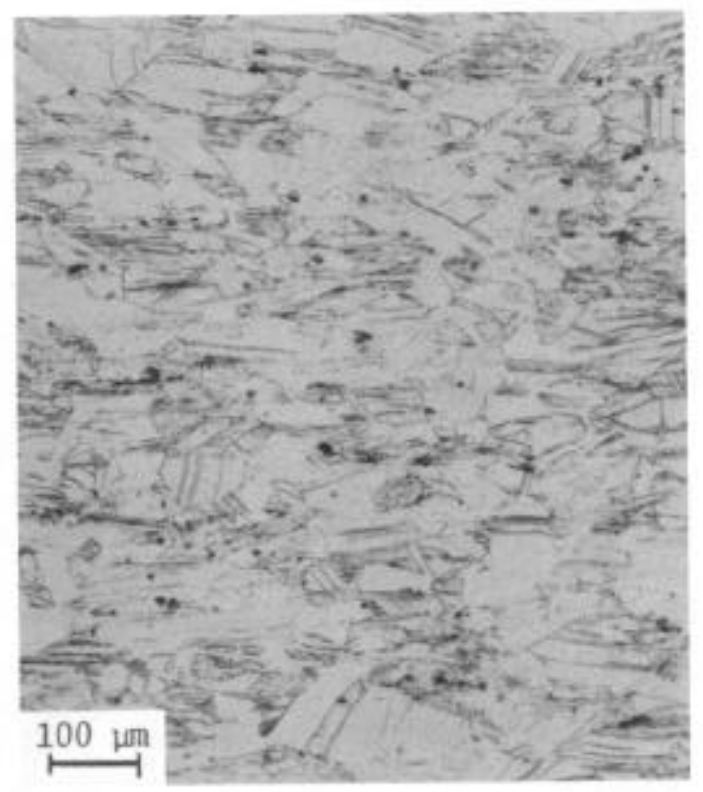

Figure 1: Optical micrograph of as-rolled material (a) $30 \%$ cold rolled, and (b) $50 \%$ cold rolled 


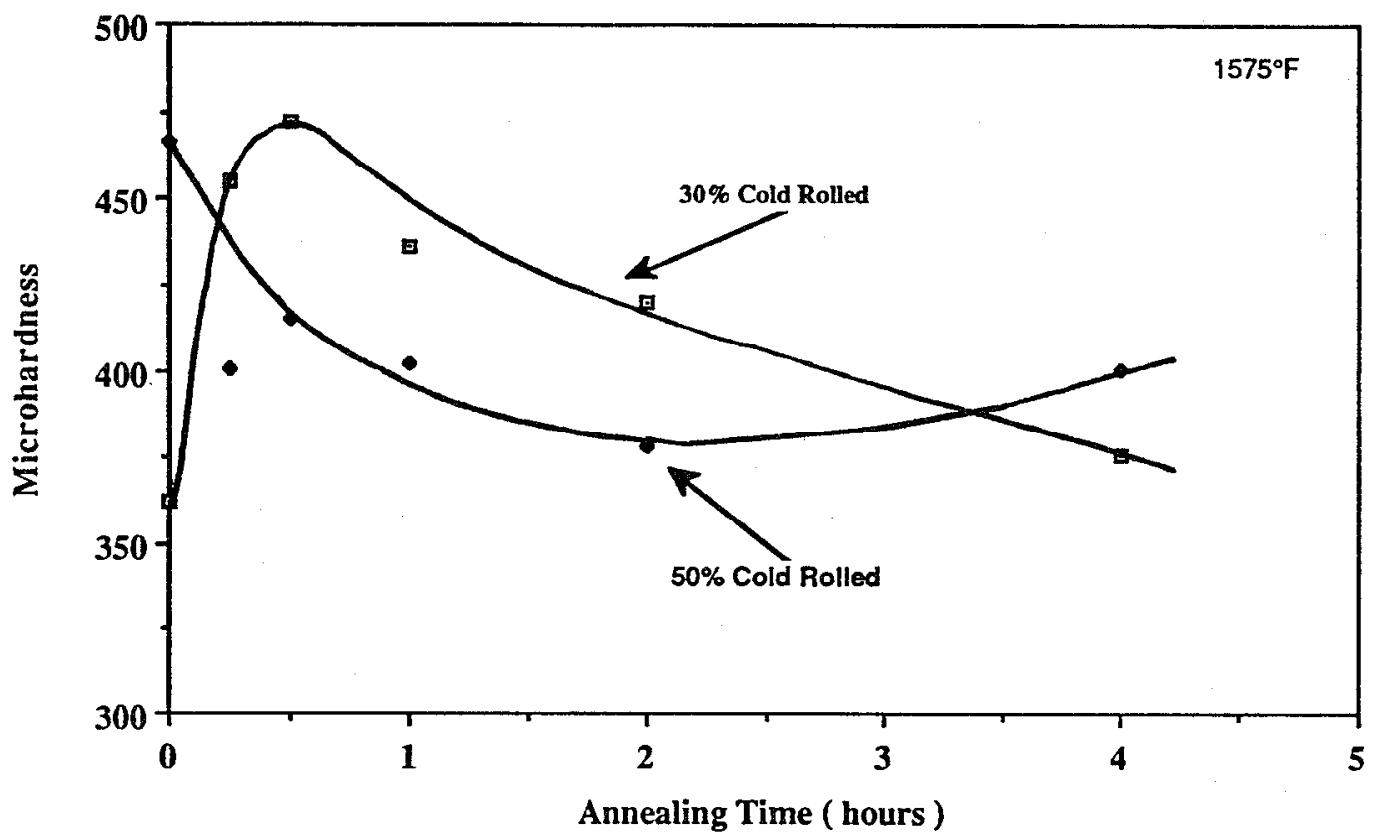

Figure 2: Microhardness Vs. annealing time at $1575^{\circ} \mathrm{F}$

Figures 3(a) and 3(b) show optical micrographs of material rolled $30 \%$ and $50 \%$, respectively after thermal exposure at $1575^{\circ} \mathrm{F}$ for 30 minutes. There is no apparent change in the grain structure for the $30 \%$ cold rolled material after 30 minutes exposure although an increase in hardness was observed. For the $50 \%$ cold rolled material, nucleation of strain free grains is observed at the grain boundaries and at some of the coarse carbide particles.

Microstructures after 4 hours at $1575^{\circ} \mathrm{F}$ are shown at $100 \mathrm{X}$ in Figure 4 and at 5,000X in Figure 5. The optical microstructures in Figure 4(a) and 4(b) show variations in the delta phase precipitation after 4 hours exposure for the $30 \%$ and the $50 \%$ rolled material, respectively. It is interesting to note that more of the delta phase has precipitated in the $50 \%$ cold rolled material compared to $30 \%$ cold rolled material. Precipitation of $\gamma^{\prime \prime} / \gamma^{\prime}$ and delta phase is observed in Figure 5 at higher magnification. In the $30 \%$ rolled material precipitation of $\gamma^{\prime \prime} / \gamma^{\prime}$ precipitates have been observed on a very fine scale and this appears to inhibit the recrystallization. In contrast, for the 50\% rolled material, precipitation of $\gamma^{\prime \prime} / \gamma^{\prime}$ is less, and delta precipitation is higher. The precipitation of delta phase does not appear to inhibit recrystallization. It seems that the lower strain enhances the precipitation of $\gamma^{\prime \prime}$ and $\gamma^{\prime}$ phase whereas higher strain in the $50 \%$ rolled samples appears to promote precipitation of delta phase. This behavior can be rationalized based on the slip behavior in this alloy. It is plausible that with increasing strain wavy slip may change over to planar slip forming slip bands and deformation twins as has been seen in nickel - cobalt based alloys (8). These slip 
a)

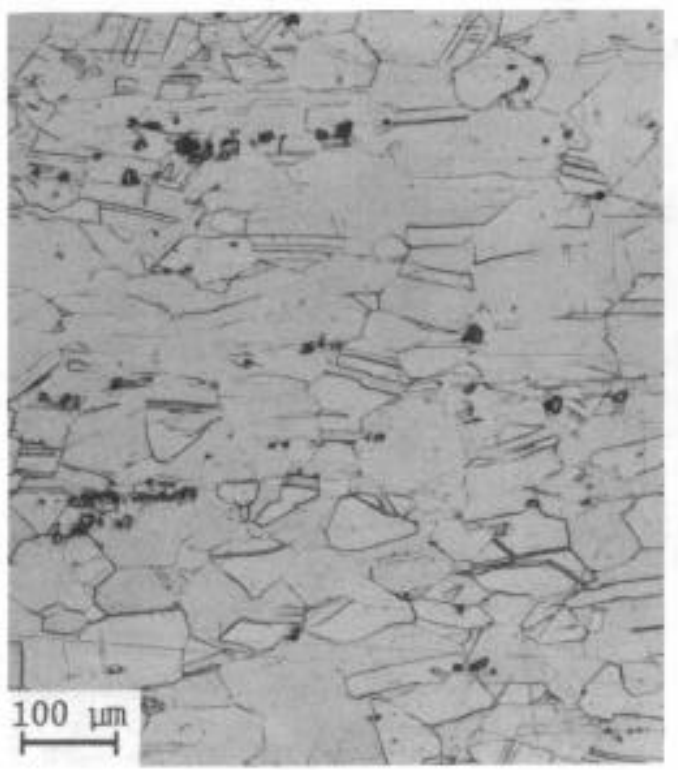

b)

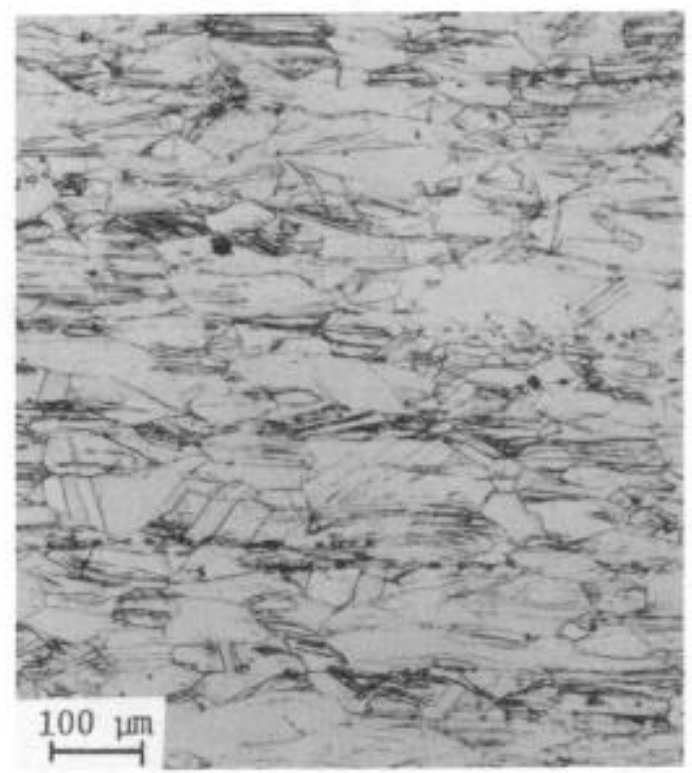

Figure 3: $\quad$ Microstructures after thermal exposure of 30 minutes at $1575^{\circ} \mathrm{F}$ (a) $30 \%$ cold rolled, and (b) $50 \%$ cold rolled (Optical)

bands and / or deformation twins may act as nucleation sites for delta precipitation and will decrease the amount of $\gamma^{\prime \prime}$ phase since there will be less niobium present to form $\gamma^{\prime \prime}$. Planar markings in the optical micrographs are indications of planar slip, however, to confirm this hypothesis transmission electron microscopy work will be carried out.

The above microstructural observations suggest that the increased hardness shown in Figure 2 for the $30 \%$ cold rolled samples heated for short times at $1575^{\circ} \mathrm{F}$ is due to precipitation of $\gamma^{\prime \prime} / \gamma^{\prime}$ and some delta precipitation. There is also precipitation of $\gamma^{\prime \prime} / \gamma$ and delta in the $50 \%$ cold rolled material heated to $1575^{\circ} \mathrm{F}$, but rapid recovery and the on-set of static recrystallization leads to rapid softening. There is more of a driving force for the nucleation to occur in the $50 \%$ cold rolled samples than the $30 \%$ rolled. The gradual increase in the hardness for the $50 \%$ cold rolled samples as a result of exposure times longer than 2 hours appears to be due to precipitation of delta phase ( see Figure 4(a) and 4(b)).

Figure 6 shows variation of microhardness with time at $1625^{\circ} \mathrm{F}$. A slight initial increase in hardness for the $30 \%$ cold rolled material and a gradual decrease in hardness for the $50 \%$ cold rolled samples are observed. For the $50 \%$ rolled material, the loss in hardness at $1625^{\circ} \mathrm{F}$ is less rapid than the loss of hardness at $1575^{\circ} \mathrm{F}$ for the same heating time. Also the 

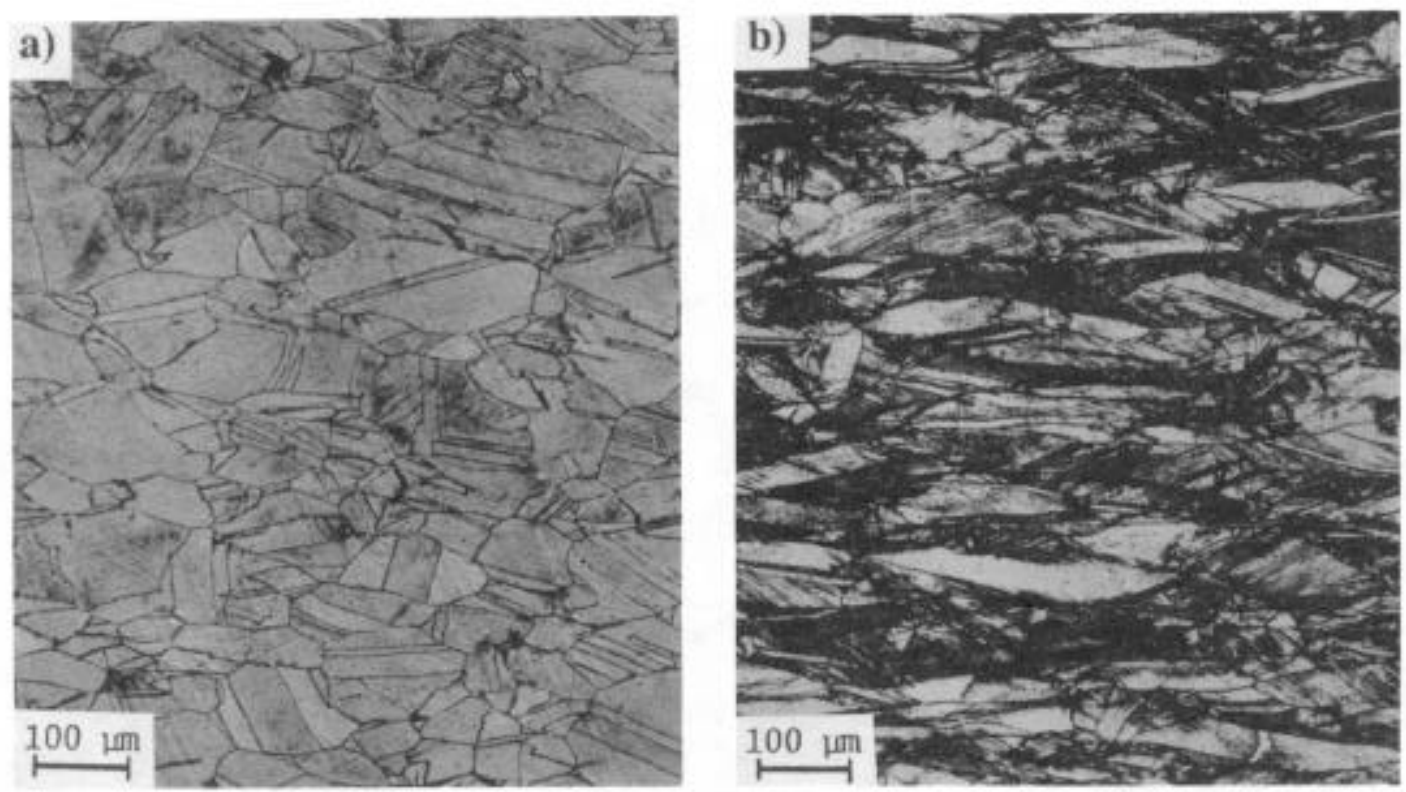

Figure 4: $\quad$ Microstructures after thermal exposure of 4 hours at $1575^{\circ} \mathrm{F}$ (a) $30 \%$ cold rolled, and (b) $50 \%$ cold rolled ( Optical )
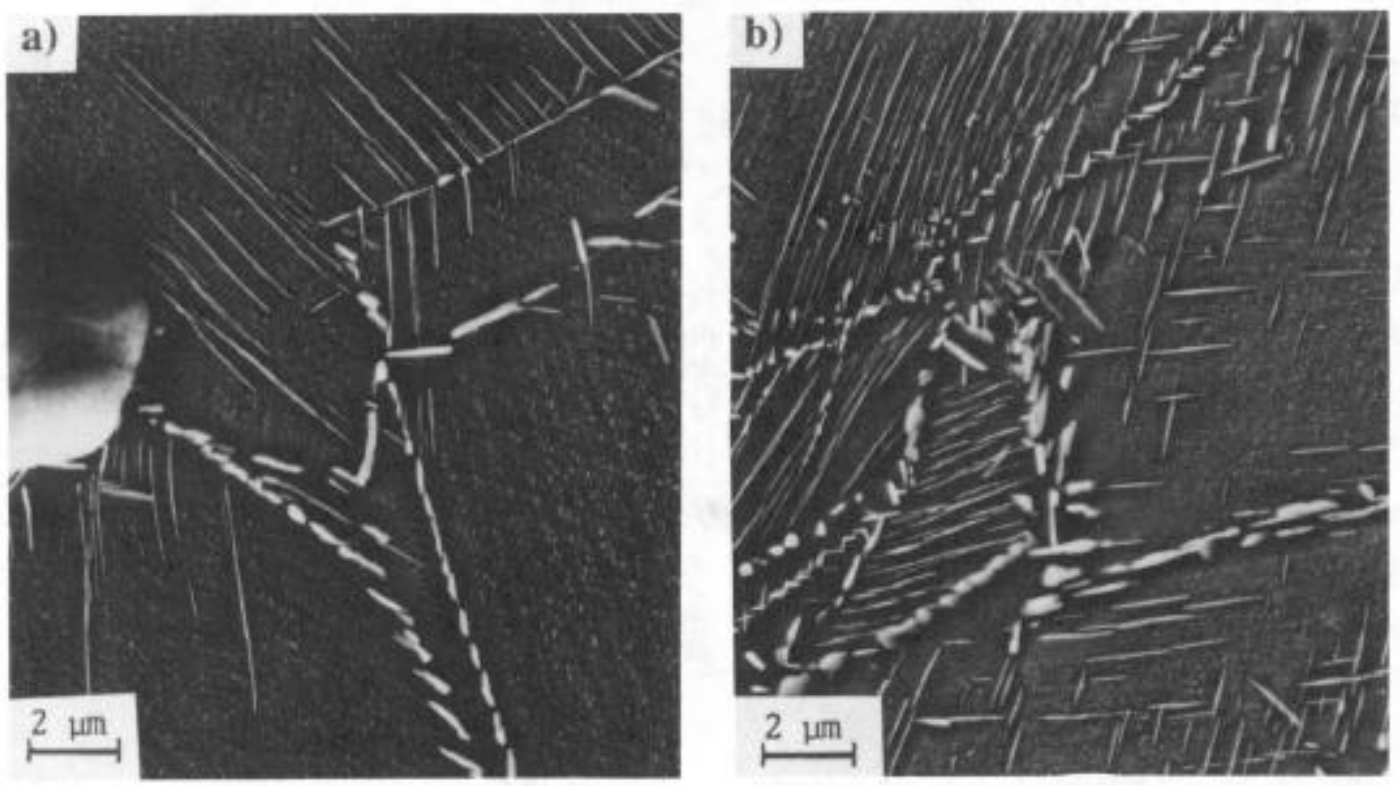

Figure 5: $\quad$ Microstructures after thermal exposure of 4 hours at $1575^{\circ} \mathrm{F}$ (a) $30 \%$ cold rolled, and (b) $50 \%$ cold rolled ( SEM ) 


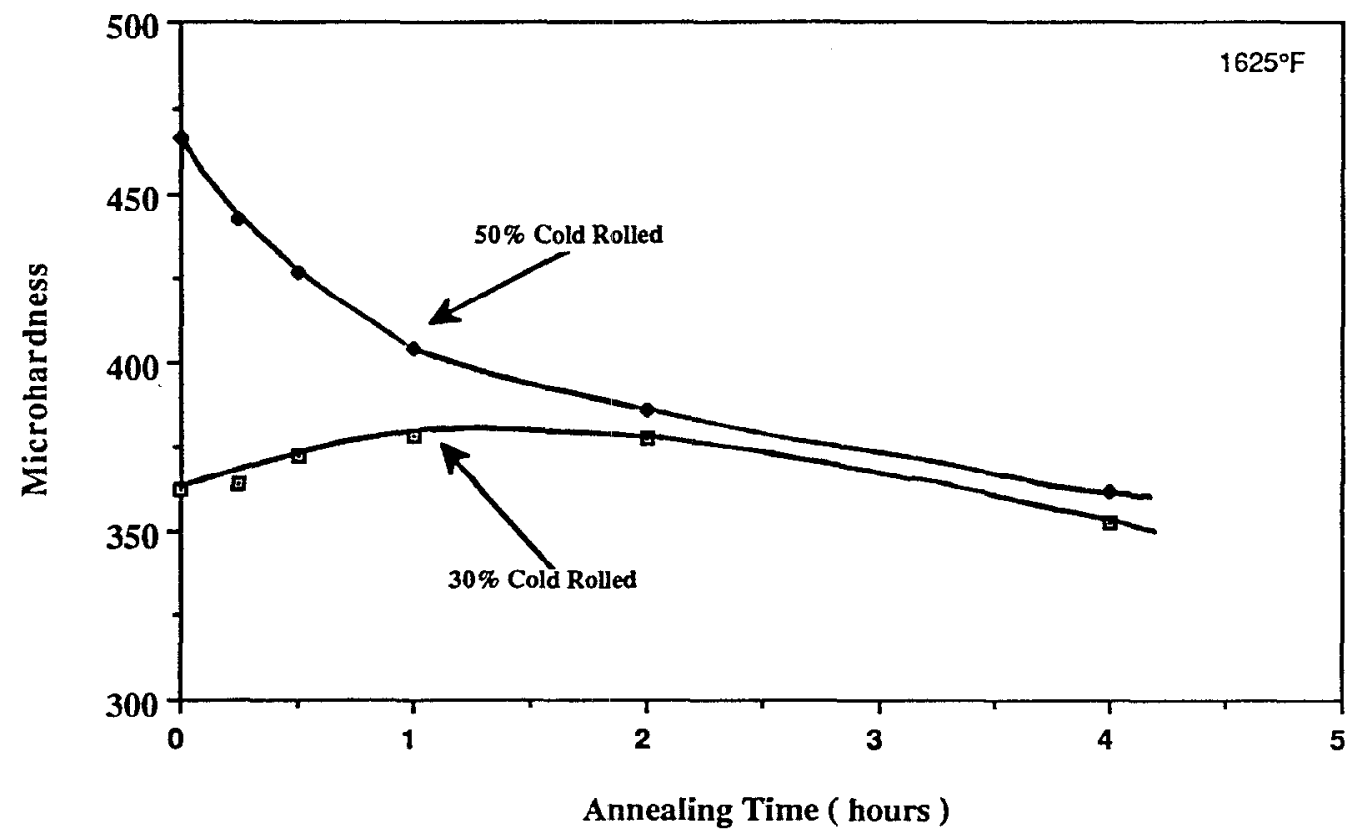

Figure 6: $\quad$ Microhardness Vs. annealing time at $1625^{\circ} \mathrm{F}$.

increase in hardness for the $30 \%$ cold rolled samples at $1625^{\circ} \mathrm{F}$ is much less than the hardness gain at $1575^{\circ} \mathrm{F}$ for the same time. Representative optical microstructures after 30 minute and 4 hour exposures at $1625^{\circ} \mathrm{F}$ are shown in Figures 7 and 8 , respectively. Once again there is no sizeable change in the grain structure with up to 4 hours exposure at $1625^{\circ} \mathrm{F}$ except that a few isolated strain free grains are seen at the grain boundaries. The precipitation of delta phase is not observed in the optical microstructures of the $30 \%$ rolled material heated at $1625^{\circ} \mathrm{F}$. Precipitation of delta phase occurred for the longer annealing times, and this is shown in Figures 8(a) and 8(b). For the 50\% cold rolled material, more of the strain free grains have nucleated at the grain boundaries, and this results in a necklace grain structure. The precipitation of delta phase primarily occurs at the prior grain boundaries, and this inhibits the grain growth of the newly recrystallized grains. A comparison of the precipitates for 4 hours exposure time at $1625^{\circ} \mathrm{F}$ in the $30 \%$ and the $50 \%$ cold rolled material is shown in Figure 9. The $\gamma^{\prime \prime} / \gamma^{\prime}$ and delta phase are present in the 30\% rolled alloy whereas only delta phase can be resolved at $5,000 \mathrm{X}$ in the $50 \%$ rolled alloy. The amount of delta phase has increased with increasing hold time.

Microhardness variations with annealing time are shown in Figures 10 and 11 for $1675^{\circ} \mathrm{F}$ and $1725^{\circ} \mathrm{F}$ exposures, respectively. At $1675^{\circ} \mathrm{F}$, a rapid loss in hardness is observed with time up to 30 minutes for both the deformation levels. After 30 minutes, the hardness increased slightly and then remained constant. Microstructural examination revealed that after 15 minutes exposure, the $50 \%$ rolled materiall is fully recrystallized and precipitation of delta 

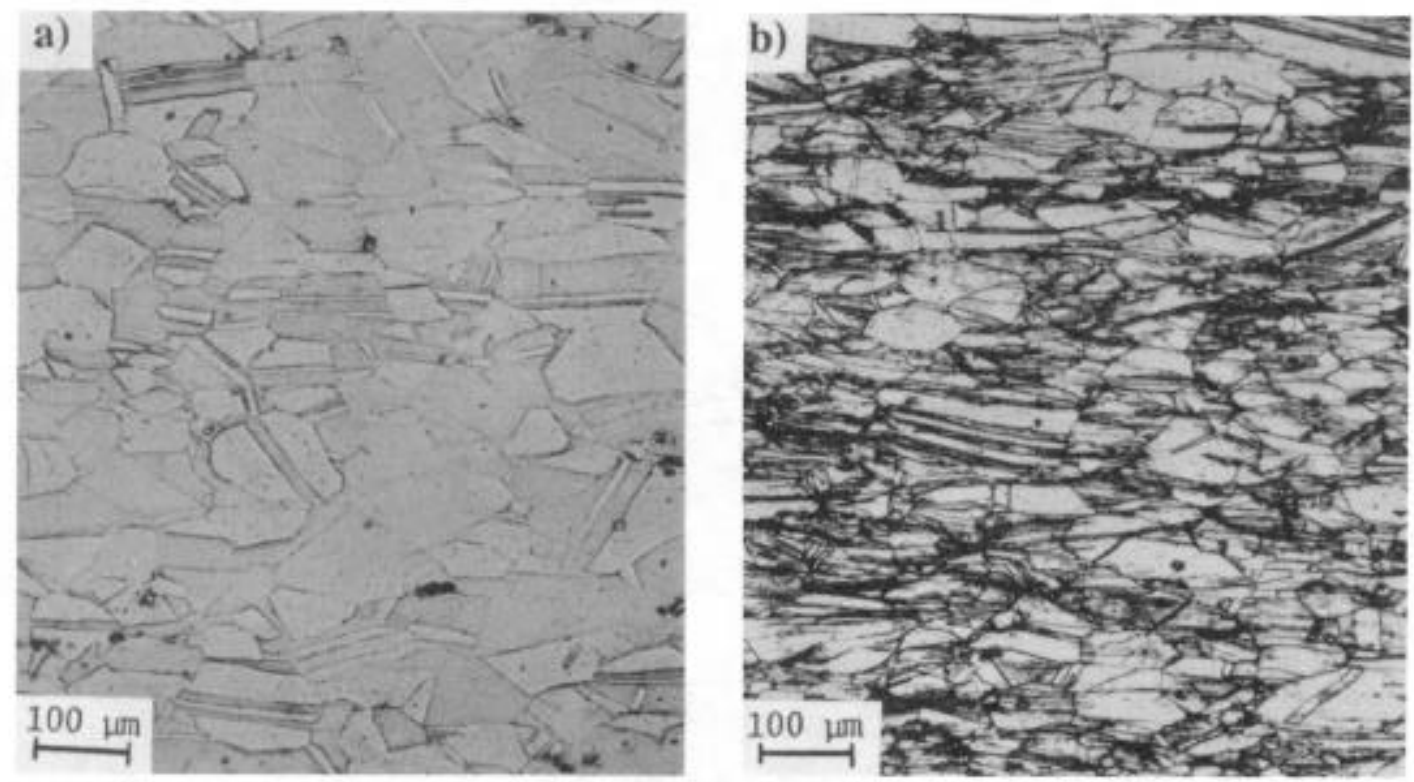

Figure 7: $\quad$ Microstructures after thermal exposure of 30 minutes at $1625^{\circ} \mathrm{F}$ (a) $30 \%$ cold rolled, and (b) $50 \%$ cold rolled (Optical)

a)

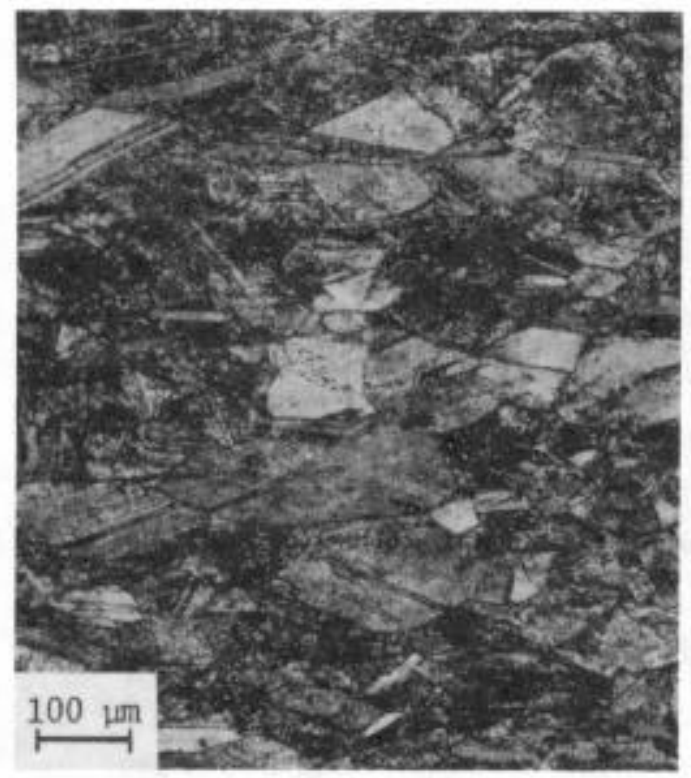

b)

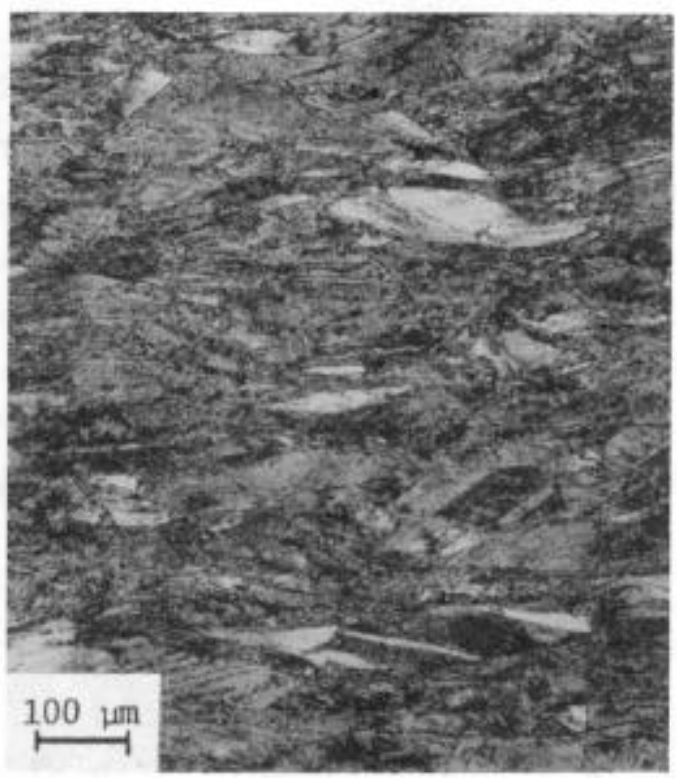

Figure 8: Microstructures after thermal exposure of 4 hours at $1625^{\circ} \mathrm{F}$ (a) $30 \%$ cold rolled, and (b) $50 \%$ cold rolled (Optical) 

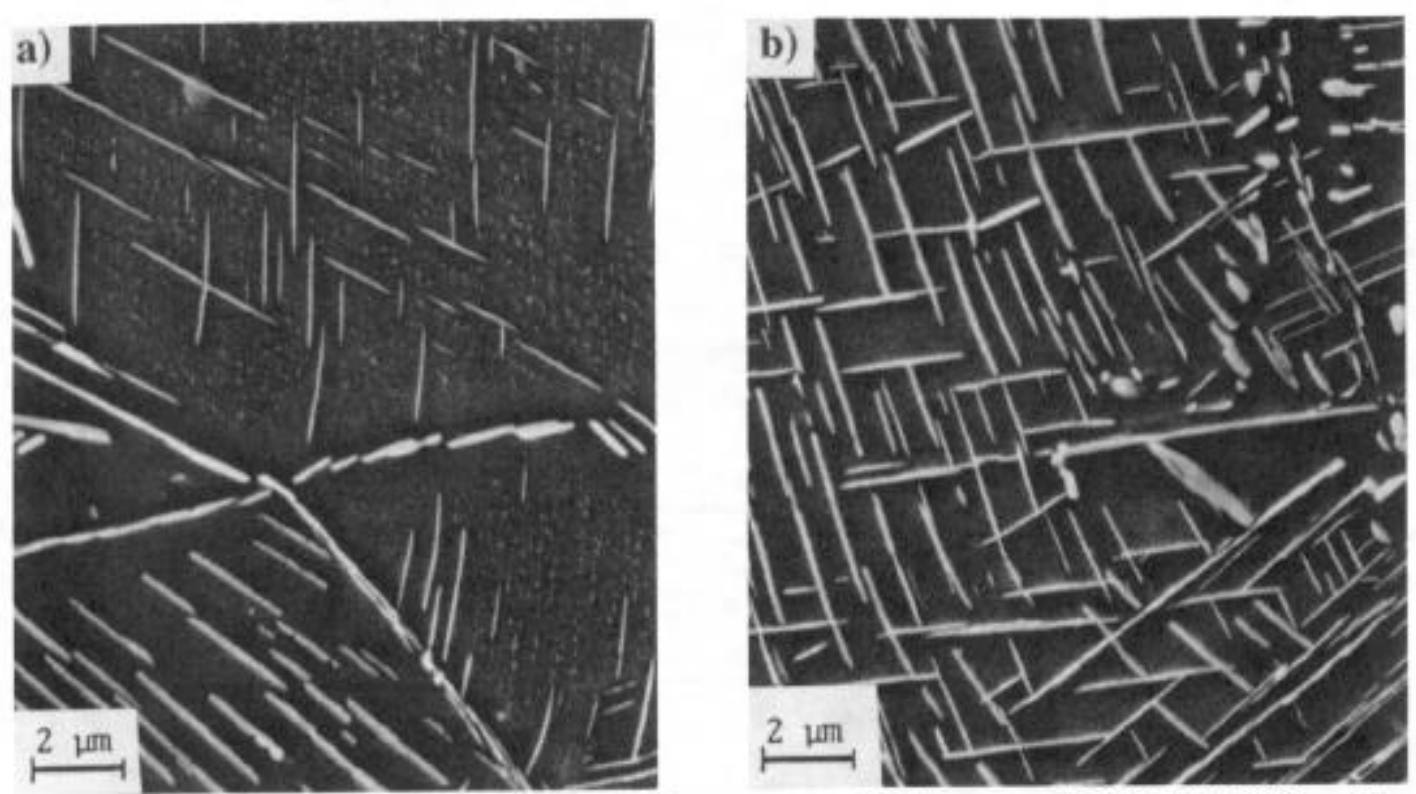

Figure 9: Microstructures after thermal exposure of 4 hours at $1625^{\circ} \mathrm{F}$ (a) $30 \%$ cold rolled, and (b) $50 \%$ cold rolled ( SEM )

phase occurred at the prior grain boundaries. For longer holding time, delta phase precipitated in other areas as well. For the $30 \%$ rolled material, recrystallization started after 15 minutes exposure and a necklace grain structure developed. With increasing time the size of the necklace grains increased until their growth was inhibited by delta precipitation.

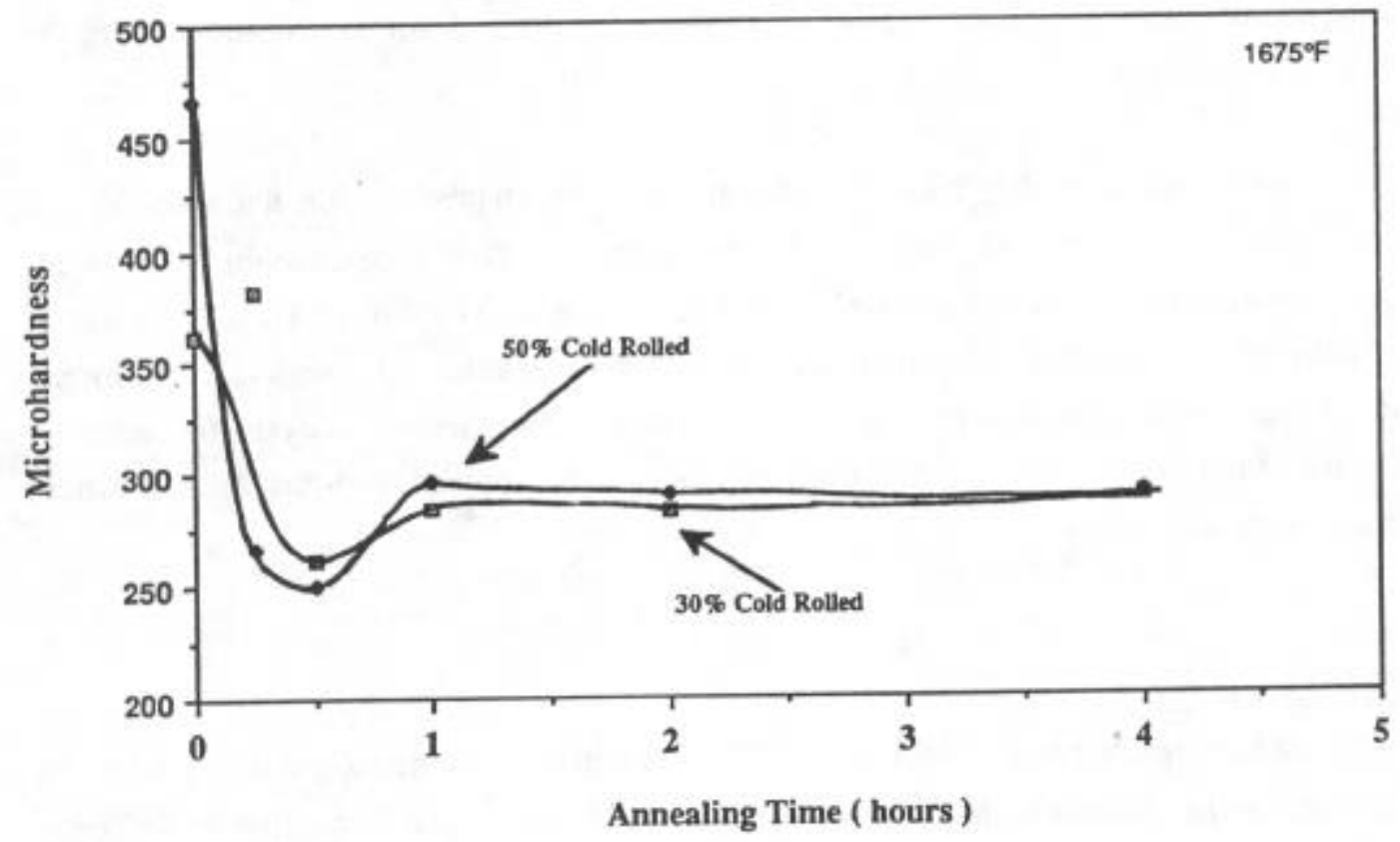

Figure 10: Microhardness Vs. annealing time at $1675^{\circ} \mathrm{F}$ 


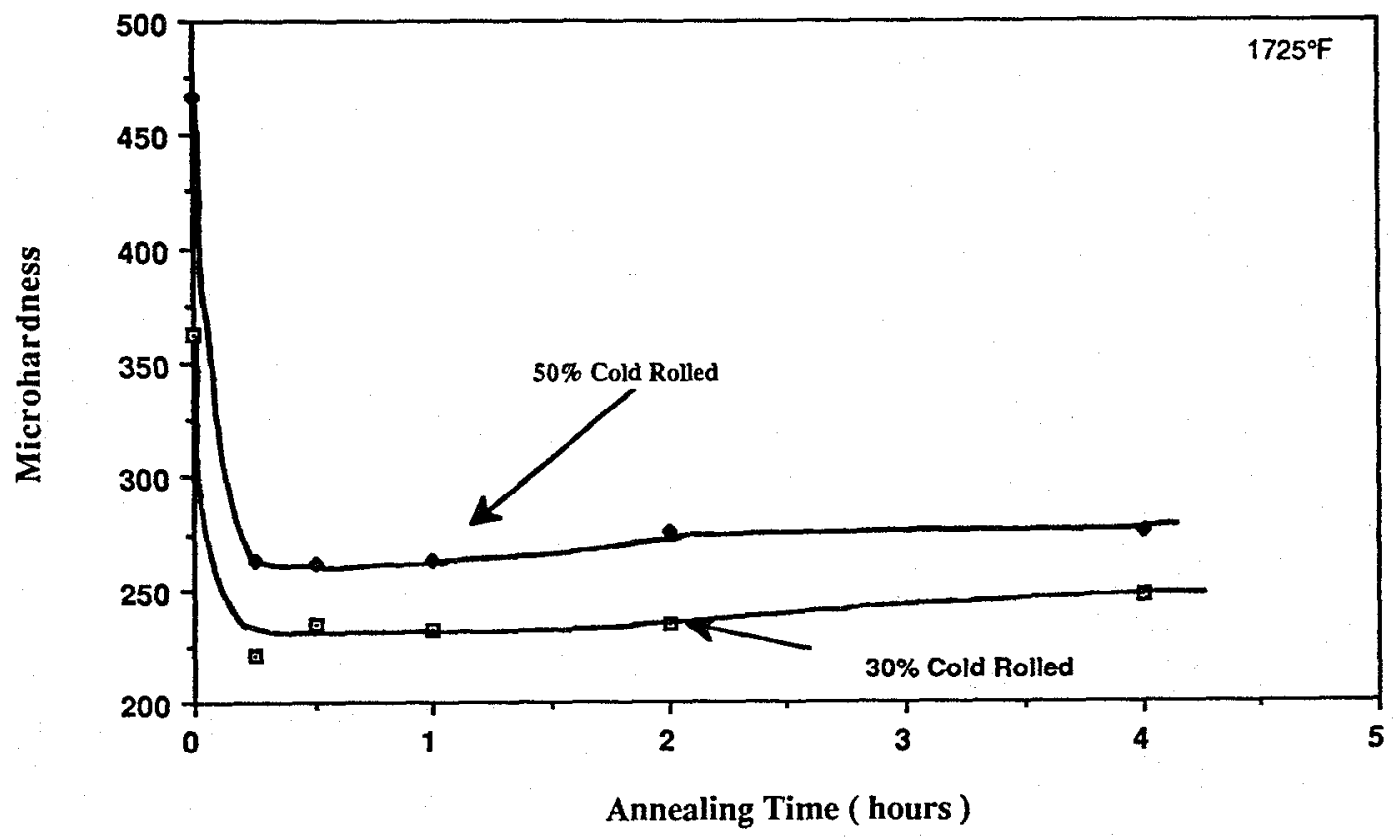

Figure 11: Microhardness Vs. annealing time at $1725^{\circ} \mathrm{F}$

At $1725^{\circ} \mathrm{F}$, hardness initially decreased sharply, and then remained constant. Microstructural examination showed that the $30 \%$ and the $50 \%$ rolled samples were fully recrystallized in just 15 minutes at this temperature. Precipitation of delta phase occurs at the prior grain boundaries before recrystallization occurs, and then continues at the grain boundaries of the recrystallized grains and in the grain interiors. It is interesting to note that the hardness after 2 and 4 hours is higher for the $50 \%$ rolled alloy compared to the $30 \%$ rolled alloy. This appears to be due to finer recrystallized grain size resulting for the $50 \%$ rolled material than for the $30 \%$ rolled material.

The above results show very interesting interactions between precipitation, and recovery and recrystallization in cold rolled Alloy 718 . Precipitation of $\gamma^{\prime \prime} / \gamma^{\prime}$ appears to inhibit recovery and recrystallization even at a reletively high temperature of $1575^{\circ} \mathrm{F}\left(0.75 \mathrm{~T}_{\mathrm{m}}\right)$. Precipitation of delta phase inhibits grain growth as has been demonstrated by others (6). Additional studies of these interactions in Alloy 718 using differential thermal analysis, transmission electron microscopy and scanning electron microscopy coupled with the microhardness changes are proceeding.

\section{Conclusions:}

1) At lower temperatures of $1575^{\circ} \mathrm{F}$ and $1625^{\circ} \mathrm{F}$, an initial hardening followed by a softening with increasing annealing time for the $30 \%$ cold rolled material, and a continuous softening for the $50 \%$ cold rolled material were observed. These changes are attributed to a difference in precipitation of $\gamma^{\prime \prime} / \gamma^{\prime}$. For the $30 \%$ cold rolled material, effects of precipitation are more 
pronounced than the effects of recovery and recrystallization which are also occurring. For the $50 \%$ cold rolled material, the driving force for recovery and recrystallization as evidenced by a continous softening are much stronger than the effects of precipitation of $\gamma^{\prime \prime} / \gamma^{\prime}$.

2) At higher temperatures of $1675^{\circ} \mathrm{F}$ and $1725^{\circ} \mathrm{F}$ for both $30 \%$ and $50 \%$ cold rolled material, hardness initially decreased rapidly, then increased slightly and remained constant. This behavior is a result of rapid initial recovery and recrystallization followed by precipitation of delta phase which inhibits grain growth.

3) Precipitation of $\gamma^{\prime \prime} / \gamma^{\prime}$ appears to inhibit recovery and recrystallization, and delta precipitation appears to inhibit grain growth during high temperature anneal of cold rolled Alloy 718.

4) At the lower annealing temperatures, precipitation of $\gamma^{\prime \prime} / \gamma^{\prime}$ is more prevalent than precipitation of delta for the $30 \%$ cold rolled material. However, precipitation of delta phase was more favorable than precipitation of $\gamma^{\prime \prime} / \gamma^{\prime}$ for the $50 \%$ cold rolled material.

5) Delta phase first precipitates in the grain boundaries of the cold rolled material, and is observed both at grain boundaries and intergranular locations of the newly recrystallized grains.

\section{References:}

1) "Recrystallization of Metallic Materials" Edited by: F. Haessner, Dr. Riederer Verlag GmbH, Stuttgart, (1978)

2) P. Cotterill and P.R. Mould: " Recrystallization and Grain Growth in Metals", John Wiley \& Sons, New York, New York, (1976)

3) "Annealing Process - Recovery, Recrystallization and Grain Growth", Edited by: N. Hansen, D.J. Jensen, T. Leffers and B. Ralph, Ris $\emptyset$ National laboratories, Roskilde, Denmark, (1986)

4) U. Koster: in "Recrystallization of Metallic Materials" (Edited by: F. Haessner), Riederer Verlag GmbH, Stuttgart, (1978), pp 215

5) J.W. Martin and R.D. Doherty: "Stability of Microstructures in Metallic Systems", Cambridge University Press, (1976)

6) "Superalloy 718- Metallurgy and Applications" Edited by E. Loria, TMS, (1989)

7) P.J. DiConza, R.R. Biederman and J.L. Burger: in Microstructural Science, Vol. 18, (Edited by: T.A. Place, J.D. Braun, W.E. White and G.F. VanderVoort), IMS, Columbus, Ohio \& ASM International, Materials Park, Ohio, (1990)

8) R.P. Singh: Ph.D. Thesis, Drexel University, Philadelphia, PA , (1987) 